\title{
Characterization of FeOOH Nanoparticles and Amorphous Silica Matrix in an FeOOH-SiO 2 Nanocomposite
}

\author{
Guido Ennas, Maria F. Casula, Sergio Marras, Gabriele Navarra, Alessandra Scano, and Giaime Marongiu \\ Dipartimento di Scienze Chimiche, Università di Cagliari, Complesso Universitario S.S. 554, Bivio per Sestu, 09042 Monserrato, Italy
}

Correspondence should be addressed to Guido Ennas, ennas@unica.it

Received 30 July 2007; Accepted 3 December 2007

Recommended by Sang-Hee Cho

A nanocomposite with an $\mathrm{FeOOH} / \mathrm{SiO}_{2}$ ratio equal to $17.7 \mathrm{wt} \%$ and the pertinent matrix, obtained by etching away the nanoparticles through reaction with hydrochloric acid, were investigated by XRD, TGA-DTA, heliostereopicnometry, BET, and TEM techniques. The study shows the presence in the nanocomposite of ferrihydrite nanoparticles phase with average dimensions around $4 \mathrm{~nm}$. The FeOOH nanoparticles structure was analyzed by synchrotron X-ray diffraction data using the distribution difference curve method. The porous structure of the matrix resulting by etching away the nanoparticles differs significantly from that of a pure $\mathrm{SiO}_{2}$ sample obtained by hydrolysis of TEOS under the same operative conditions followed in the nanocomposite preparation.

Copyright (c) 2008 Guido Ennas et al. This is an open access article distributed under the Creative Commons Attribution License, which permits unrestricted use, distribution, and reproduction in any medium, provided the original work is properly cited.

\section{INTRODUCTION}

Nanocomposite materials, composed of nanometric metal or metal-oxide particles embedded in amorphous matrices, present a variety of interesting magnetic, electric, and catalytic properties that are strongly dependent on nanoparticles size and on their distribution within the matrix $[1,2]$. During recent years, several metal and metal oxide-silica nanocomposites have been prepared in our laboratories by sol-gel method and characterized by a multitechnique approach [3-5]. These highly porous materials obtained by drying the gels either at ambient conditions or by supercritical solvent evaporation receive increasing attention in physics, chemistry, and medicine. One of the most intriguing questions which is still open is to identify the steps which lead to nanoparticles formation and to clarify how their interaction with the matrix influences its texture and structure and, from the other point of view, how matrix texture and structure influence particle formation and its size and distribution within the matrix.

In the preparation route to $\gamma-\mathrm{Fe}_{2} \mathrm{O}_{3}-\mathrm{SiO}_{2}$ nanocomposite, it has been observed that around $350^{\circ} \mathrm{C}$ an intermediate iron hydroxyoxide phase, $\mathrm{FeOOH}$, is present which eventually gives rise to $\gamma-\mathrm{Fe}_{2} \mathrm{O}_{3}$ by further thermal treatment [6]. A sample of nanocomposite with an $\mathrm{FeOOH} / \mathrm{SiO}_{2}$ ratio equal to $17.7 \mathrm{wt} \%$ and one of the pertinent matrix, obtained by etching away the nanoparticles through reaction with hydrochloric acid, were investigated by TGA-DTA, heliostereopicnometry, BET, XRD, and TEM techniques. The structure of $\mathrm{FeOOH}$ nanoparticles was investigated by the analysis of synchrotron X-ray diffraction data, using the difference method which was developed and tested in the analysis of several glasses $[7,8]$.

\section{EXPERIMENTAL SECTION}

The nanocomposite samples were prepared by a sol-gel technique mixing an ethanolic solution of tetraethoxysilane (TEOS, Aldrich 98\%; Ethanol, EtOH, Carlo Erba 95\%) with an ethanolic solution of $\mathrm{Fe}\left(\mathrm{NO}_{3}\right)_{3} \cdot 9 \mathrm{H}_{2} \mathrm{O}$ (Aldrich $98 \%$ ). The hydrolysis-condensation reactions were promoted by adding few drops of nitric acid (Carlo Erba 70\%) in order to keep $\mathrm{pH}$ value close to 0.6 . The metal solution concentration was selected in order to obtain nanocomposite samples with $\mathrm{FeOOH} / \mathrm{SiO}_{2}$ weight ratio equal to $17.7 \%$. Under these conditions, the molar ratios of TEOS/EtOH/water are 0.02, 0.83, and 0.15 , respectively. After stirring for one hour, the clear sol was poured in a teflon becker and allowed to gel in air at room temperature (RT). The fresh alcogel was powdered and heat treated at $350^{\circ} \mathrm{C}$ in order to obtain the xerogel sample. During the first hour, calcination was performed under argon atmosphere in order to avoid organics combustion 


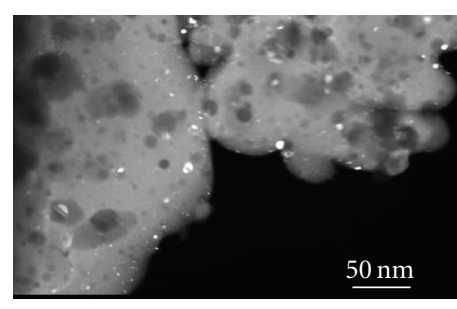

(a)

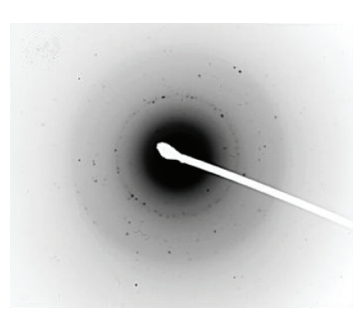

(b)

FIGURE 1: TEM dark field image and electron diffraction pattern of the nanocomposite sample.

and consequent sample overheating; treatment was then continued in air for one more hour in order to remove the residual water and organics. The xerogel, in the form of a brown-orange powder, was then transferred into a desiccator and cooled down to RT. The nanocomposite xerogel was divided into two portions: one portion was submitted to textural and structural investigations while the other was dispersed in an aqueous hydrochloric acid solution $(\approx 6 \mathrm{M})$ and stirred for one hour at $75^{\circ} \mathrm{C}$. The resulting white powder, repeatedly washed with distilled water until complete elimination of chloride ions, was then dried in an oven at $200^{\circ} \mathrm{C}$ for twelve hours and then transferred into a desiccator and cooled down to RT. As discussed later, this procedure is effective in removing the dispersed phase from the nanocomposite sample, and therefore, the sample obtained will be referred to as matrix. As a reference, a pure silica sample was also prepared by adopting the sol-gel procedure followed in the preparation of the nanocomposite xerogels.

Thermal gravimetric analysis (TG) and simultaneous differential thermal analysis (DTA) were carried out on a Mettler-Toledo TGA/SDTA 851 apparatus. Thermal analysis data were collected in the $25-1000^{\circ} \mathrm{C}$ range under oxygen flow (heating rate $=10^{\circ} \mathrm{C} \cdot \mathrm{min}^{-1}$; flow rate $=50 \mathrm{~mL} \cdot \mathrm{min}^{-1}$ ).

$\mathrm{X}$-ray diffraction data were recorded at room temperature using MoK $\alpha$ radiation $(\lambda=0.7107 \AA)$ on a D500 $\theta-2 \theta$ Siemens diffractometer equipped with a graphite monochromator on the diffracted beam. The scans were performed within the angular region $4^{\circ} \leq 2 \theta \leq 130^{\circ}$; at least 100000 counts were collected at each point.

Synchrotron X-ray diffraction data were collected on beamline ID15 B at the ESRF (Grenoble, France). The energy of the photons was set at $88925.2 \mathrm{eV}$ corresponding to a wavelength of $0.1395 \AA$. The sample was held in the beam using a $1 \mathrm{~mm}$ thick aluminum plate. The sample was packed into a $5 \times 5 \mathrm{~mm}$ cavity in the centre of the plate, which was then covered on either side with kapton film to hold the powder in the place. The X-ray scattering patterns were recorded using a 2-dimensional MAR 345 image detector. Details on experimental data treatment and correction are given in [9].

TEM bright field (BF) and dark field (DF) images and selected-area electron diffraction (SAED) patterns were obtained on a JEOL 200CX microscope equipped with a tungsten cathode operating at $200 \mathrm{kV}$. The samples were dispersed in n-octane and dropped on a holey carbon-coated copper grid.

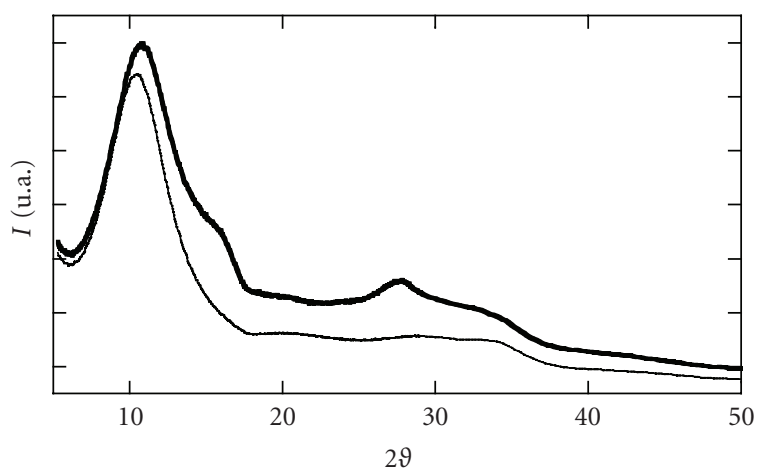

FIGURE 2: X-ray diffraction patterns of the nanocomposite (thick line) and of the matrix (thin line) obtained by laboratory apparatus $(\lambda=\operatorname{MoK} \alpha)$.

Textural analysis was carried out on a Sorptomatic 1990 system (Fisons Instruments) by determining the nitrogen adsorption/desorption isotherms at $77 \mathrm{~K}$. Before analysis, the samples were heated up to $200^{\circ} \mathrm{C}$ at a rate of $1^{\circ} \mathrm{C} \cdot \mathrm{min}^{-1}$ under vacuum. The specific surface area $(S)$ and the pore size range were assessed by the Barrett-Emmett-Teller (BET) and the Barrett-Joyner-Halenda (BJH) methods, respectively, $[10,11]$.

Density measurements were carried out at room temperature by heliostereopicnometry on a Quantochrome mod SPY-2 apparatus.

\section{RESULTS AND DISCUSSION}

TEM dark field image of the nanocomposite, reported in Figure 1, shows a uniform dispersion within the silica matrix of almost spherical nanoparticles with an average particle size around $4 \mathrm{~nm}$. The SAED pattern consists of two diffuse diffraction rings which correspond to interplanar distances in agreement with the bump at $15^{\circ} 2 \vartheta$ and the small peak around $28^{\circ} 2 \vartheta$ in the XRD pattern of the nanocomposite (Figure 2), these peaks are characteristics of the socalled two-lines ferrihydrite phase $[12,13]$. This presence is the only appreciable difference between the XRD patterns of nanocomposite and matrix samples, which are both dominated by the broad peak centered at $10^{\circ} 2 \vartheta$, characteristic of the amorphous silica diffraction spectra [14].

The most significant thermal features of both nanocomposite and matrix happen below $200^{\circ} \mathrm{C}$, as shown by the ther- 


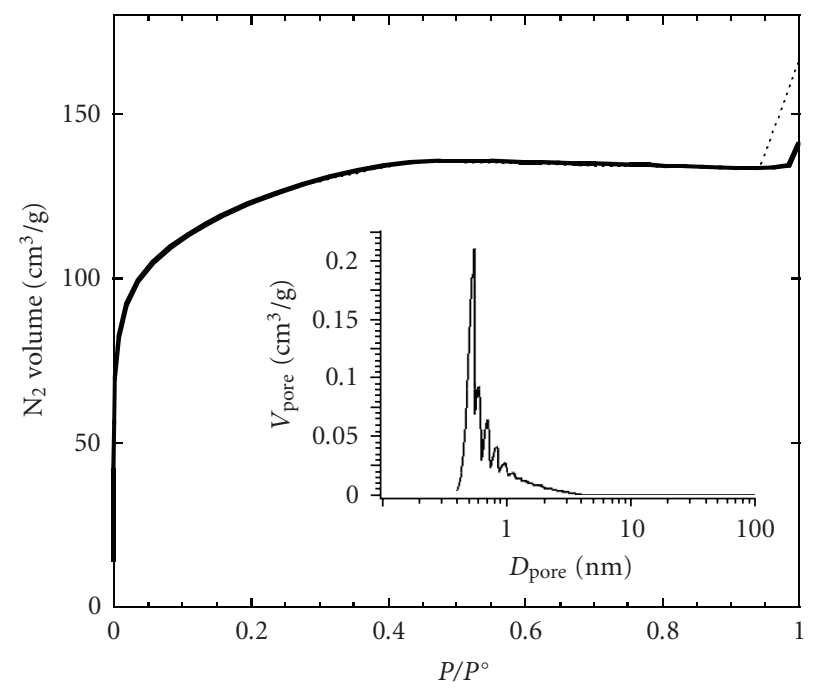

(a)

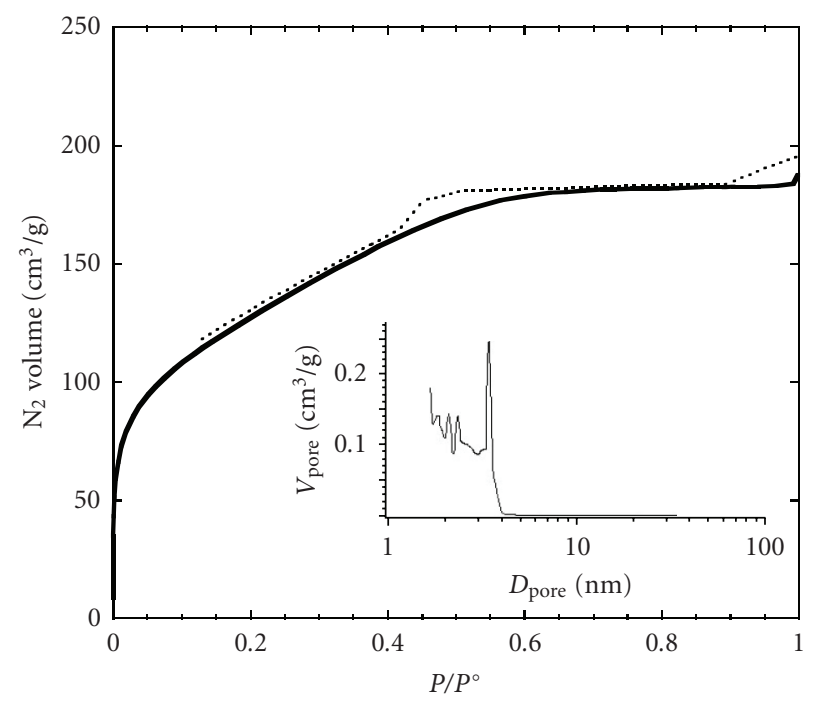

(b)

FIGURE 3: $\mathrm{N}_{2}$-physisorption curves recorded at $77 \mathrm{~K}$ for nanocomposite (a) and pertinent matrix (b). Calculated pore size distributions are reported in the inset.

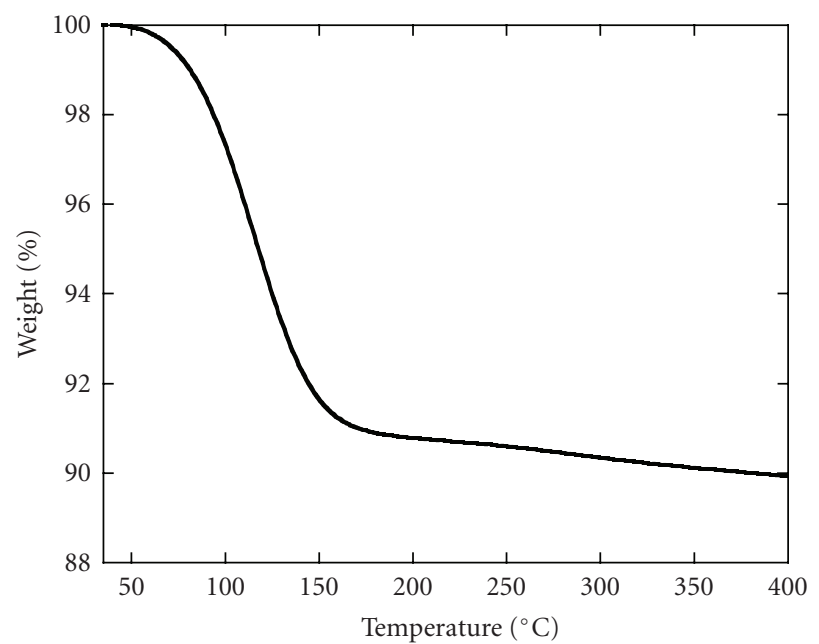

(a)

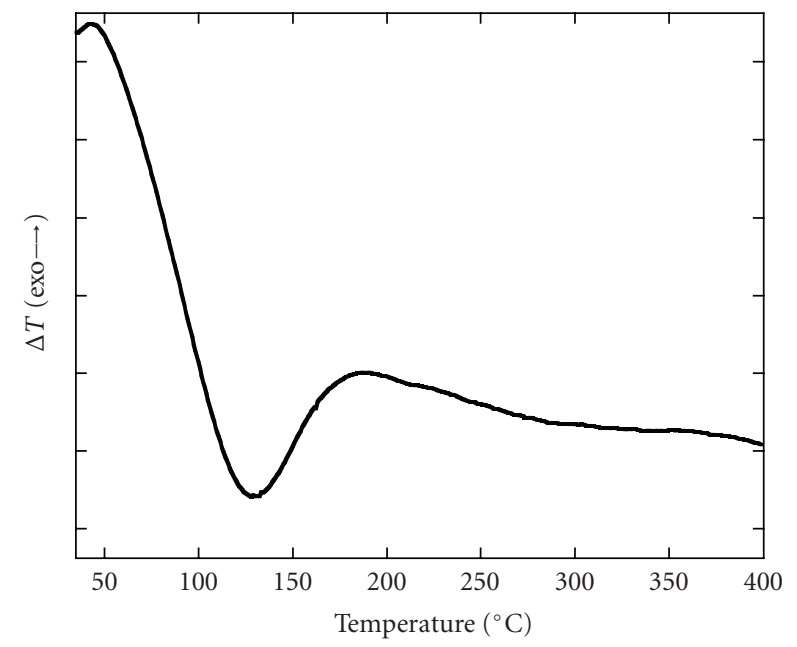

(c)

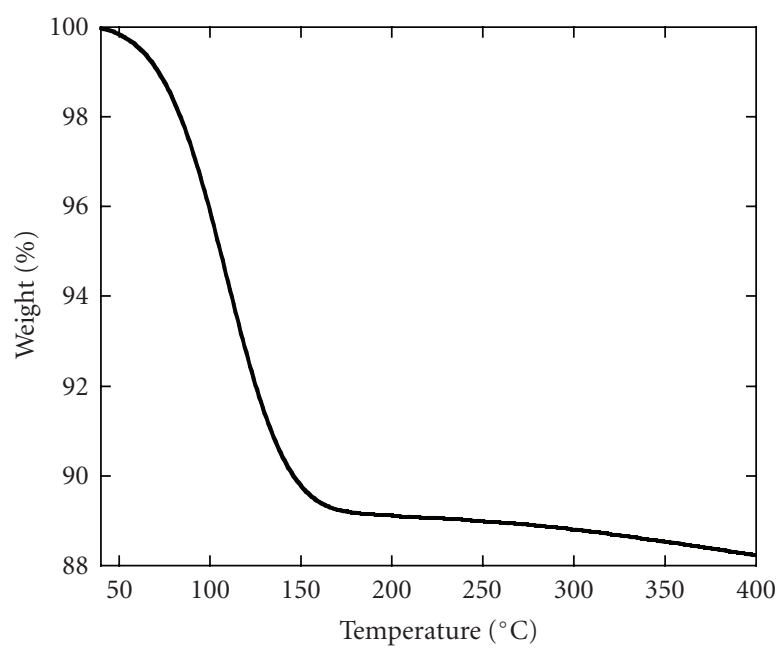

(b)

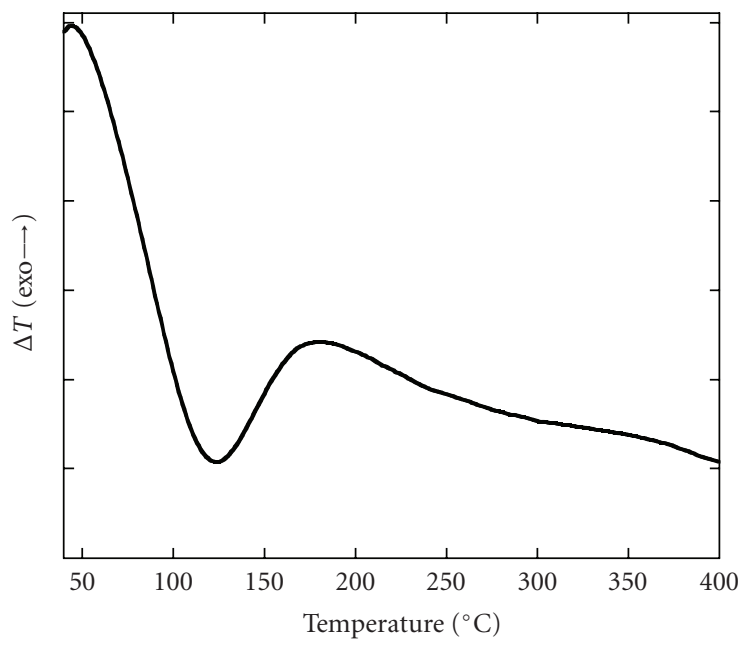

(d)

Figure 4: (a), (c) TG and DTA curves for nanocomposite and (b), (d) pertinent matrix samples. 


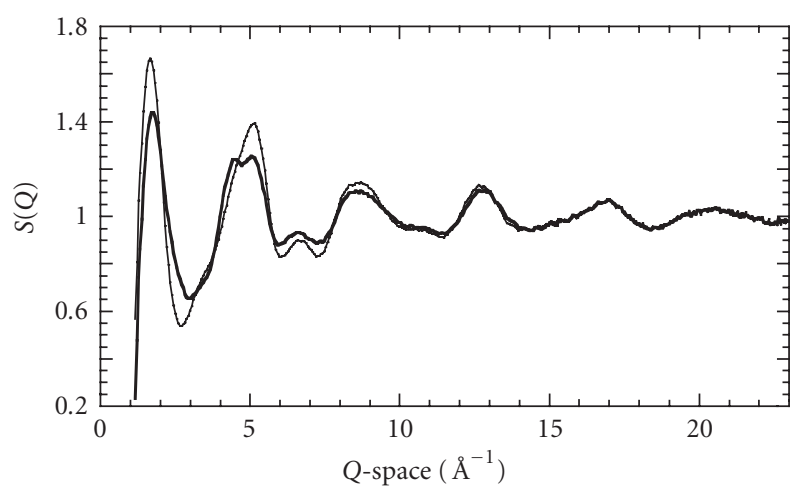

(a)

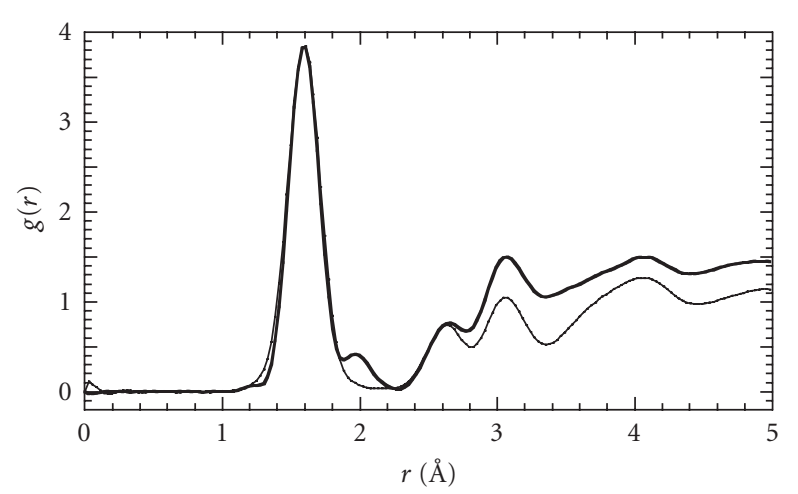

(b)

FIgURE 5: The total scattering structure functions $S(Q)$ of the nanocomposite (thick line) and of the matrix (thin line) (a), pair distribution functions $g(r)$ of the nanocomposite (thick line) and of the matrix (thin line) (b).

mograms reported in Figure 4. Endothermic DTA peaks and corresponding TGA steps are ascribable to the loss of the water adsorbed by the samples within the desiccator during cooling to room temperature, since the presence of silica in the desiccator does not avoid humidity capture from the samples. The matrix weight loss is equal to $11 \%$, from which a silica content equal to $89 \%$ can be inferred. The nanocomposite weight loss, equal to $9 \%$, includes a partial contribution due to $\mathrm{FeOOH}$ nanoparticles dehydration. According to data reported in the literature [12], the weight loss of FeOOH is in the range of $13 \%$ to $22 \%$ when temperature increases from RT up to $200^{\circ} \mathrm{C}$. By taking into account this contribution, the nanocomposite stoichiometry can be assumed as $\mathrm{SiO}_{2} 79 \%$, $\mathrm{FeOOH} 14 \%, \mathrm{H}_{2} \mathrm{O} 7 \%$.

Density values, determined at room temperature by heliostereopicnometry, are $2.15 \mathrm{~g} \cdot \mathrm{cm}^{-3}$ and $1.95 \mathrm{~g} \cdot \mathrm{cm}^{-3}$ for nanocomposite and matrix, respectively, which are in agreement with the values calculated according to the assumed stoichiometries.

Figures 3(a) and 3(b) report the physisorption isotherms of the nanocomposite and matrix samples, respectively. The nanocomposite exhibits a reversible isotherm which can be considered as a type I type IV with a prevalent type I contribution, compatible with a microporous structure. This is also in agreement with the pore size distribution reported in the inset, which suggests the presence of micropores. The isotherm of the matrix sample can still be considered as a type I type IV composite isotherm; the contribution arising from mesoporosity, however, is more relevant in this sample as suggested by the presence of a small hysteresis loop. The pore size distribution shows a narrow peak due to the presence of mesopores with average diameter of $3.8 \mathrm{~nm}$. These results indicate that the textural modification observed in the matrix with respect to the nanocomposite is related to the appearance of voids as a consequence of nanoparticles dissolution. This fact is confirmed by the average value of mesopores diameter, about $3.8 \mathrm{~nm}$, which is compared to the average diameter of nanoparticles. Both isotherms are definitely different from that of the pure $\mathrm{SiO}_{2}$ sample obtained by hydrolysis of TEOS under the same operative conditions followed in the nanocomposite preparation. In fact, this sample is wholly microporous and shows a type I isotherm (not shown). In order to exclude the possible effect of hydrochloric acid on the silica texture, physisorption isotherms were carried out on this sample after acid treatment. Their perfect coincidence confirms that acid attack does not affect $\mathrm{SiO}_{2}$ texture.

The differences in the physisorption isotherms suggest that $\mathrm{SiO}_{2}$ matrix adapts its texture to host the nanoparticles, which can be easily etched away by chemical attack without any influence on the short range order of $\mathrm{SiO}_{2}$. On this assumption, a detailed analysis of synchrotron X-ray diffraction data was carried out in order to better investigate the nanoparticles structure. The structure functions $S(Q)$ $[15,16]$ of the two samples, shown in Figure 5(a), evidence a very close similarity at high $Q$ values, as a result of the preservation of short range order in the silica network. According to the Faber and Ziman formalism [16], the structure function $S(Q)$ is obtained from the coherently scattered intensity $I_{c}(Q)$ and the Laue monotonic scattering term $I_{L}(Q)$,

$$
S(Q)=\frac{I_{c}(Q)-I_{L}(Q)}{\left\langle f^{2}\right\rangle},
$$

where

$$
\left\langle f^{2}\right\rangle=\sum_{\alpha} c_{\alpha} f_{\alpha}^{2}(Q),
$$

and $Q=4 \pi \sin (\theta) / \lambda$ is the modulus of the scattering vector; $f_{\alpha}$ and $c_{\alpha}$ are the atomic scattering factor and the concentration of the $\alpha$ species, respectively.

At low values, and in particular at $Q=2.5 \AA^{-1}$ and $4.5 \AA^{-1}$, the scattering contribution of nanoparticles is evident in the nanocomposite pattern. This contribution is even more clear in the pair distribution functions $g(r)$ (see Figure 5(b)) calculated by Fourier transform of the pertinent $S(Q)$ and scaled to a stoichiometric unit containing one silicon atom. The nanocomposite function shows at $\approx 2.1 \AA$ and $\approx 3.1 \AA$ the contribution of $\mathrm{Fe}-\mathrm{O}$ and $\mathrm{Fe}$-Fe distances, respectively.

Under the assumption that the structure of the matrix remains substantially unaltered when nanoparticles are 


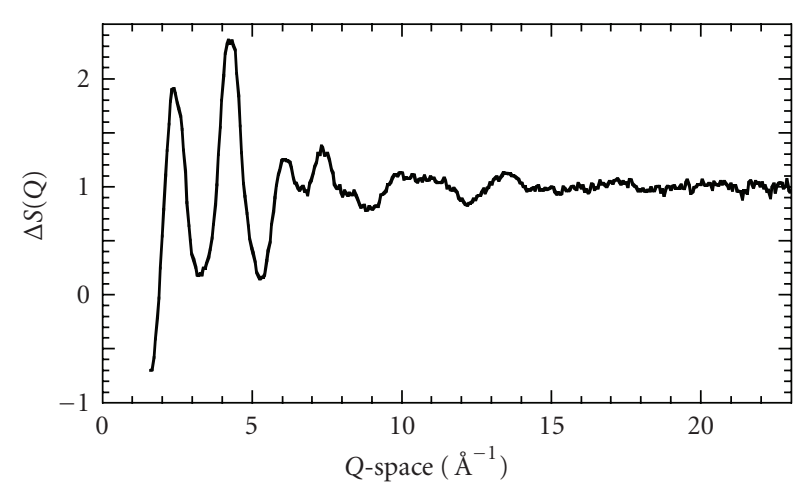

(a)

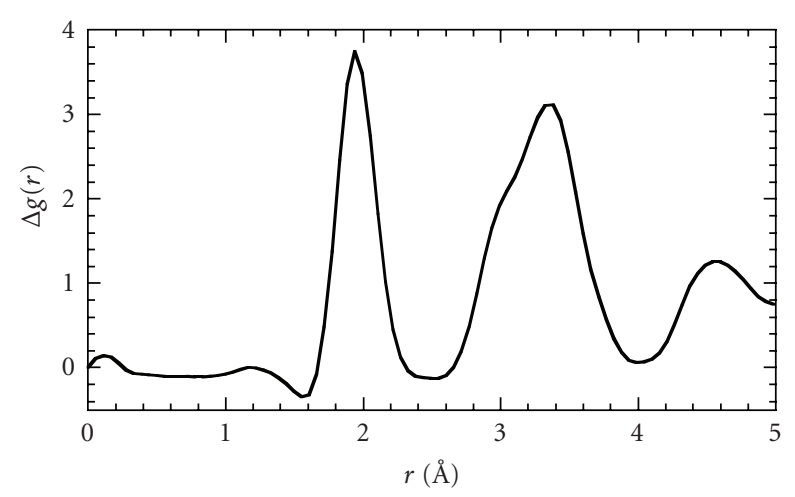

(b)

Figure 6: The difference structure function $\Delta S(Q)$ (a) and the difference pair distribution functions $\Delta g(r)$ (b).

removed, their contribution to the total experimental structure function was evaluated by subtracting the experimental coherent scattering intensity of the $\mathrm{SiO}_{2}$ matrix from that of the nanocomposite, according to a procedure which was successfully adopted in the structural analysis of glasses [7, 8]. In the calculated difference structure function $\Delta S(Q)$ (see Figure 6(a)), the contributions due to $\mathrm{Si}-\mathrm{O}, \mathrm{O}-\mathrm{O}$, and $\mathrm{Si}-\mathrm{Si}$ pairs are practically cancelled, while those due to $\mathrm{Fe}-\mathrm{O}$ and $\mathrm{Fe}-\mathrm{Fe}$ are definitely enhanced. This effect is markedly evident in the difference pair distribution function $\Delta g(r)$ (see Figure 6(b)) where the peaks at $1.6 \AA$ and $2.6 \AA$ practically disappear. $\Delta g(r)$ is dominated by a peak at $2.0 \AA$, which compares to $\mathrm{Fe}-\mathrm{O}$ distances in $\mathrm{FeO}_{6}$ octahedral polyhedra, and by overlapped peaks at $3.1 \AA$ and $3.4 \AA$ characteristics of FeFe distances for linked polyhedra. The results are in agreement with a recent study on ferrihydrite based on a very accurate analysis of pair distribution function obtained by high-energy X-ray total scattering [17]. It shows that the primary difference between the so-called 2- and 6-line ferrihydrite is the limited size of the coherent scattering domains rather than a fundamental difference in atomic arrangement, confirming the power of pair distribution function analysis described in detail in the book of Egami and Billinge [15]. As a matter of fact, the $\Delta g(r)$ function worked out by the $\mathrm{X}$-ray diffraction data collected with laboratory apparatus (see Figures 1 and 2 in Supplementary Material available online at doi:10.1155/2007/61816 does not differ significantly from that obtained with synchrotron radiation data, suggesting the general feasibility of the analysis.

\section{CONCLUSIONS}

The investigation suggests that, in the nanocomposite sample, iron-oxyhydroxide nanoparticles are embedded into the pores of the silica matrix without any significant bonding interactions, and they can be easily etched away by the action of hydrochloric acid. Electron microscopy and synchrotron $\mathrm{X}$-ray investigations confirm that $4 \mathrm{~nm}$ nanoparticles present in the sample treated at $350^{\circ} \mathrm{C}$ consist of ferrihydrite which eventually transform to $\gamma-\mathrm{Fe}_{2} \mathrm{O}_{3}$ by further increasing the sample temperature up to $700^{\circ} \mathrm{C}$. We interpret this data assuming that in the sol-gel transformation hydrated ferric oxyhydroxide nanoparticles are formed within the $\mathrm{SiO}_{2}$ matrix. During this stage, the matrix adapts its texture to host the nanoparticles, and the tendency of the nanoparticles to grow is counterbalanced by the increasing rigidity of the $\mathrm{SiO}_{2}$ network which limits the pore size.

\section{ACKNOWLEDGMENTS}

This study was supported by the Università di Cagliari and the MIUR through the project TEPSI. Synchrotron XRD measurements were performed by Dr. K.O.Drake at ESRF in Grenoble.

\section{REFERENCES}

[1] H. Singh Nalwa, Handbook of Nanostructured Materials and Nanotechnology, Academic Press, San Diego, Calif, USA, 2000.

[2] K. J. Klabunde, Nanoscale Materials in Chemistry, Wiley Interscience, New York, NY, USA, 2001.

[3] G. Ennas, A. Falqui, S. Marras, C. Sangregorio, and G. Marongiu, "Influence of metal content on size, dispersion, and magnetic properties of iron-cobalt alloy nanoparticles embedded in silica matrix," Chemistry of Materials, vol. 16, no. 26, pp. 5659-5663, 2004.

[4] A. Corrias, G. Ennas, G. Mountjoy, and G. Paschina, "An Xray absorption spectroscopy study of the Fe $\mathrm{K}$ edge in nanosized maghemite and in $\mathrm{Fe}_{2} \mathrm{O}_{3}-\mathrm{SiO}_{2}$ nanocomposites," Physical Chemistry Chemical Physics, vol. 2, no. 5, pp. 1045-1050, 2000.

[5] G. Piccaluga, A. Corrias, G. Ennas, and A. Musinu, Sol-Gel Preparation and Characterization of Metal and Metal-Oxide Silica Nanocomposites, Materials Science Foundations, vol. 13, Trans Tech Publications, Uetikon, Switzerland, 2000.

[6] G. Ennas, A. Musinu, G. Piccaluga, et al., "Characterization of iron oxide nanoparticles in an $\mathrm{Fe}_{2} \mathrm{O}_{3}-\mathrm{SiO}_{2}$ composite prepared by a sol-gel method," Chemistry of Materials, vol. 10, no. 2, pp. 495-502, 1998.

[7] M. Magini, A. F. Sedda, G. Licheri, et al., "On the coordination of iron ions in sodium borosilicate glasses I. A wide angle Xray diffraction investigation," Journal of Non-Crystalline Solids, vol. 65 , no. 1, pp. 145-159, 1984.

[8] G. Ennas, A. Musinu, G. Piccaluga, G. Pinna, and M. Magini, "Short-range order in a NASIGLAS sample by X-ray diffraction," Chemical Physics Letters, vol. 141, no. 1-2, pp. 143-148, 1987. 
[9] K. O. Drake, A multi-technique study of the structural evolution of selected silicate-based sol-gel materials, Ph.D. thesis, University of Warwick, Coventry, UK, 2006.

[10] F. Rouquerol, J. Rouquerol, and K. S. W. Sing, Adsorption by Powders and Porous Solids: Principles, Methodology and Applications, Academic Press, London, UK, 1999.

[11] S. Brunauer, P. H. Emmet, and E. Teller, "Adsorption of gases in multimolecular layers," Journal of the American Chemical Society, vol. 60, no. 2, pp. 309-319, 1938.

[12] R. A. Eggleton and R. W. Fitzpatrick, "New data and a revised structural model for ferrihydrite," Clays and Clay Minerals, vol. 36, no. 2, pp. 111-124, 1988.

[13] U. Schwertmann and R. M. Cornell, Iron Oxides in the Laboratory, Wiley-VCH, Weinheim, Germany, 2000.

[14] A. Corrias, G. Ennas, G. Licheri, et al., "Diffraction techniques and short range order in vitreous materials," Trends in Chemical Physics, vol. 2, pp. 79-87, 1992.

[15] T. Egami and S. J. L. Billinge, Underneath the Bragg Peaks. Structural Analysis of Complex Materials, Pergamon Materials Series, Elsevier, Oxford, UK, 2003.

[16] T. E. Faber and J. M. Ziman, "A theory of the electrical properties of liquid metals," Philosophical Magazine, vol. 11, no. 109, pp. 153-173, 1965.

[17] F. M. Michel, L. Ehm, G. Liu, et al., "Similarities in 2- and 6-line ferrihydrite based on pair distribution function analysis of X-ray total scattering," Chemistry of Materials, vol. 19, no. 6, pp. 1489-1496, 2007. 

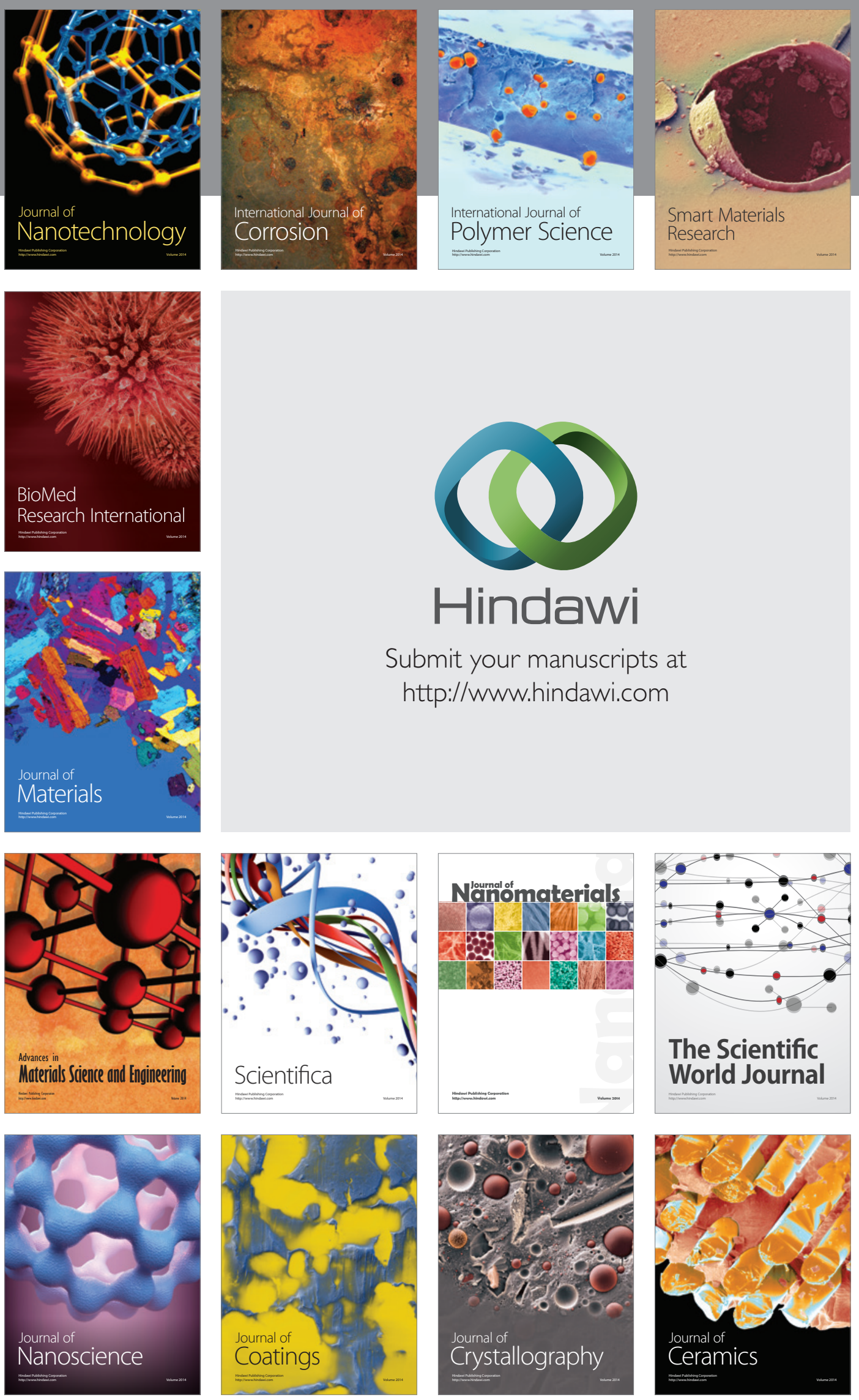

The Scientific World Journal

Submit your manuscripts at

http://www.hindawi.com

\section{World Journal}

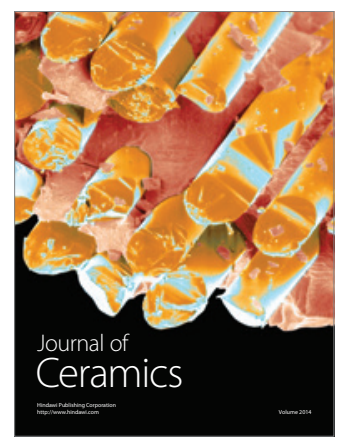

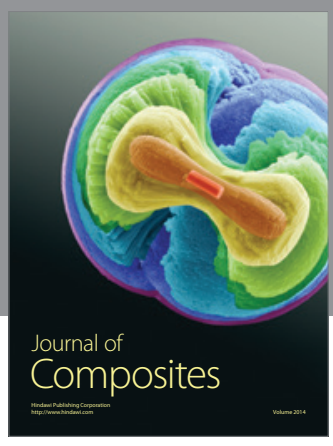
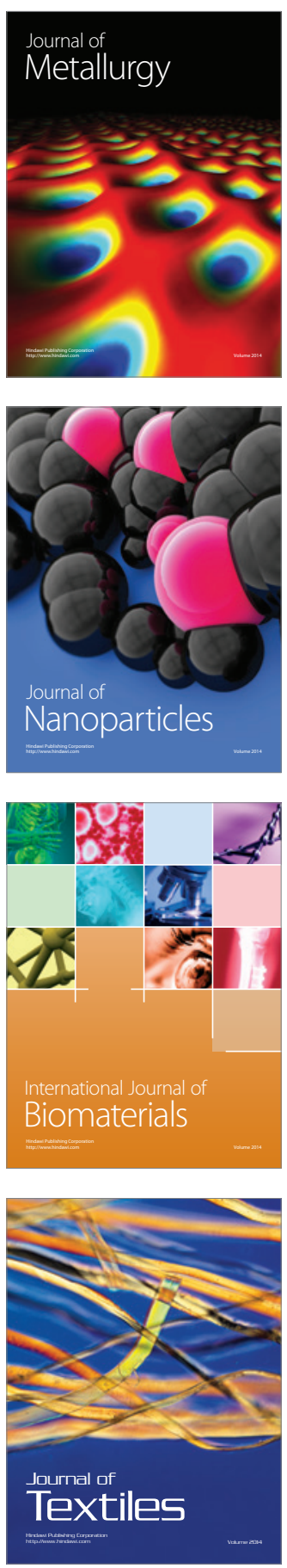